\title{
LEVONORGESTREL-RELEASING INTRAUTERINE SYSTEM IN ADENOMYOSIS; PREDICTORS FOR RESPONSE AND CLINICAL OUTCOME
}

\author{
FADIA J ALIZZI ${ }^{1}$, HIND ABDUL KHALIQ SHOWMAN ${ }^{1}$, HAYDER A FAWZI ${ }^{2}$
}

${ }^{1}$ Department of Obstetric Gynecology and Infertility, Al-Mustansiriyah College of Medicine, Baghdad, Iraq. ${ }^{2}$ Department of Pharmacy, Baghdad Teaching Hospital, Baghdad, Iraq. E-mail: fadiaalizzi46@gmail.com

Received: 04 May 2018, Revised and Accepted: 30 July 2018

\section{ABSTRACT}

Objectives: The aim is to detect clinical and ultrasonographic characters that predict the response of adenomyosis to levonorgestrel-releasing intrauterine system (LNG-IUS) and to evaluate the clinical efficacy and the time needed to show a response.

Methods: A prospective single-arm study conducted in the Obstetrics and Gynaecology Department Al-Yarmouk Teaching Hospital in Baghdad/Iraq from August 2015 to March 2018. Women with symptomatic adenomyosis with age 39 years and above and who completed their families had been enrolled in this study. LNG-IUS was used as a treatment; the outcome measure was to evaluate its effect in improving the symptoms and the time needed to show a clinical response. Multivariate analysis was used to assess the contribution of the clinical and ultrasonographic parameters to the prediction of the response to LNG-IUS.

Results: Over the mean duration of follow-up period of the study (22.7 \pm 9.9 months), there was a significant improvement in menstrual blood loss, dysmenorrhea, and hemoglobin ( $\mathrm{Hb}$ ) with significant decrease in uterine volume $(\mathrm{p}<0.001)$. The time to show response was as early as 3 months and the first 6 months is the best time to predict failure. Initial menstrual blood loss and Hb were good predictors to show response while uterine volume an excellent one (positive predictive value $80 \%$ and negative predictive value $97.2 \%$ ).

Conclusion: Levonorgestrel-releasing intrauterine device is an effective treatment of symptomatic adenomyosis in term of time to response and duration of response. The presenting $\mathrm{Hb}$, menstrual blood loss, and uterine volume are useful predictors of response.

Keywords: Adenomyosis, Levonorgestrel-releasing intrauterine system, Uterine volume.

(C) 2018 The Authors. Published by Innovare Academic Sciences Pvt Ltd. This is an open access article under the CC BY license (http://creativecommons. org/licenses/by/4. 0/) DOI: http://dx.doi.org/10.22159/ajpcr.2018.v11i12.27109

\section{INTRODUCTION}

Adenomyosis of the uterus is a common condition among women in their $4^{\text {th }}$ and $5^{\text {th }}$ decades of life and is thought to affect $1 \%$ of women [1]. It occurs when there is a disruption in the normal interface between the endometrial basal layer and the myometrium, causing the invasion of ectopic endometrial glands into the myometrium. This invasion can be either diffuse (adenomyosis) or focal (adenomyoma) [2].

A reliable diagnose of adenomyosis can be made by the combination of clinical history, gynecological examination, and transvaginal 2D and 3D ultrasound. In addition, Doppler sonography and magnetic resonance imaging might help to determine adenomyosis, especially in cases with combined uterine fibroids [3]. The diagnosis depends on triad of clinical manifestations composed of the abnormal uterine bleeding (50\%), secondary dysmenorrhea (30\%), and an enlarged, tender uterus [4].

Hysterectomy was previously recommended as a definitive treatment for adenomyosis; however, this may not be acceptable to some patients [5]. A reversible medical treatment alternative to hysterectomy does now exist the levonorgestrel-releasing intrauterine system (LNGIUS). This device has been widely evaluated in terms of contraceptive efficacy and idiopathic menorrhagia, and it is highly effective in the treatment of hydroxymethylbutyrate in perimenopausal women and has been shown to be extremely effective in treating the symptoms associated with adenomyosis [6,7]. Moreover, LNG-IUS seems to demonstrate significant and comparable improvements in hemoglobin (Hb) levels to hysterectomy in treating symptomatic adenomyosis, and although both of them lead to improvements in health-related quality of life, LNG-IUS seems to have superior effects on psychosocial life [8].
LNG-IUS had been effectively used to treat adenomyosis through a reduction in thickness of the myometrial junctional zone and total uterine volume [9-11]. The reduction of menstrual blood loss is due to both direct effect of levonorgestrel on adenomyosis foci with decidualization and an increase in apoptosis in endometrial glands and stroma [12].

The LNG-IUS has fewer side effects in comparison to other oral treatment used, in contrast with relatively low serum levels, locally high concentrations of LNG in the endometrium and adjacent tissues [13].

Factors that can predict LNG-IUS treatment response or discontinuation due to expulsion or failure to show a response in women with adenomyosis were not well assessed $[5,14]$.

The aim of this study was to detect clinical and ultrasonographic characters that predict the response of adenomyosis to LNG-IUS and to evaluate the clinical efficacy and the time needed to show response.

\section{MATERIALS AND METHODS}

A prospective single-arm study conducted in the Obstetrics and Gynaecology Department Al-Yarmouk Teaching Hospital in Baghdad/ Iraq from August 2015 to March 2018 after ethical and scientific committee approval of the Obstetrics and Gynaecology Department.

Women with adenomyosis diagnosed clinically and by ultrasound had been recruited after taking informed written consent from all participants; patients with symptomatic adenomyosis, age 39 years and above and who completed their families had been enrolled in this study. Women with concomitant leiomyomas and other uterine pathology had been excluded as well as women who did not complete their family. 
Detailed history, examination, and baseline $\mathrm{Hb}$ were performed for all participant followed by ultrasound (transabdominal and transvaginal) to confirm the diagnosis of adenomyosis and exclude other concomitant uterine pathology.

Pictorial blood loss assessment chart was used to assess menstrual blood loss/cycle and menorrhagia defined when the chart score was more than 100 which was, in turn, equivalent to blood loss of more than $80 \mathrm{~mL}[15]$

The severity of dysmenorrhea and pelvic pain was graded by a $10 \mathrm{~cm}$ visual analog pain scale (VAS), where mild pain $=1-3$, moderate $=4-6$, sever $=7-9$, and sever disabling pain $=10[16]$.

The ultrasound features used to diagnose adenomyosis in this study were the presence of myometrial cysts, linear myometrial striations, poor delineation of the endomyometrial junction, heterogeneous myometrium, and a globular and/or asymmetric uterus [17]. Uterine volume based on the sonographic parameters was calculated using the formula for a prolate ellipsoidals; Volume $=0.5233 \times \mathrm{D} 1 \times \mathrm{D} 2 \times \mathrm{D} 3$ where, D1 = maximum length (longitudinal dimension), D2 = maximum AP dimension, and D3 = maximum width (transverse dimension) [14]. All the patients were subjected to an outpatient endometrial biopsy to rule out other associated possible endometrial pathology [18].

LNG-IUS (Mirena-Bayer, Germany) was inserted in the uterus at the end of the cycle by a specialist in strict accordance with the operating instructions and its place in utero was confirmed immediately by ultrasound and reconfirmed again 10-14 days after.

Medical management using nonsteroidal anti-inflammatory drugs, antifibrinolytics tranexamic acid if not contraindicated for the first 2-3 months with cycle was given, and anemia was assessed and corrected [19].

Each patient was asked to come for regular follow-up after Mirena insertion $3 \mathrm{~m}, 6 \mathrm{~m}$ and then at the end of $1^{\text {st }}$ year and $2^{\text {nd }}$ year was full history to see the clinical response regarding menstrual blood loss and pain score and to notify any possible encountered side effect. At each visit, transabdominal and transvaginal ultrasound was done to measure the uterine volume and to confirm that the Mirena is in place and not partially or completely displaced.

Failure was defined as expulsion or discontinuation of Mirena use due to failure to show a response or because of its side effects.

\section{Statistical analysis}

Anderson darling test was to assess normality of data, Chi-square test, or Fisher exact test used to analyze the discrete variables. Two independent samples t-test used to analyze the differences in means between two groups, for paired group paired t-test was used (normally distributed data), while Wilcoxon U test used for non-normally distributed data. Receiver operator curve used to assess the validity of different parameters. SPSS 20.0.0 (Chicago, IL), MedClac 14.8.1, and GraphPad Prism 7.0 software package used to make the statistical analysis, $\mathrm{p}$ value considered when appropriate to be significant if $<0.05$

\section{RESULTS}

A total of 46 women with symptomatic adenomyosis were evaluated. The basic clinical characters of the participants are shown in Table 1. The mean age of the women was $44.5 \pm 2.5$ (39-49) years, and the mean number of parity was $3.6 \pm 0.9(2-6)$. Before insertion of LNG-IUS, the mean menstrual blood loss using PMAC was $144.1 \pm 25.9 \mathrm{ml}$, mean pain $3.65 \pm 1.04$ using VAS, and the mean uterine volume was $139.8 \pm 33.2$.

After insertion of LNG-IUS - there was a significant reduction in bleeding volume from baseline to 3 months $(144.1 \pm 25.9$ to $123.5 \pm 29.0)$, there was significant reduction from 3 months to 6 months after using Marina $(70.2 \pm 12.7)$, there was again significant reduction from 6 months to 12 months after using Marina (28.2 \pm 8.3$)$, and finally there was significant further reduction from 12 months to 24 months after using Marina (25.9 \pm 7.1), as illustrated in Fig. 1.

There was significant reduction in median dysmenorrhea from VAS (3-4) to (2-3), there was significant change in medina VAS score from 3 months to 6 months after using Marina 2 (1-2), there was significant change in median VAS score from 6 months to 12 months after using Marina $0(0-1)$, and finally there was no significant change from 12 months to 24 months after using Marina $0(0-1)$, as illustrated in Fig. 2.

At baseline uterine volume was $131.8 \pm 25.5 \mathrm{~mm}^{3}$ which reduced significantly to $111.1 \pm 22.3 \mathrm{~mm}^{3}$ after 6 months, after 12 months of using Mirena it reduced significantly to $93.4 \pm 14.2 \mathrm{~mm}^{3}$ and finally after another 12 months ( 2 years) it continue to reduced significantly to $82.3 \pm 10.1 \mathrm{~mm}^{3}$, as illustrated in Fig. 3 .

There was a significant increase in $\mathrm{Hb}$ value from baseline to the end of follow-up (10.3 $\pm 0.4-11.3 \pm 0.7, \mathrm{p}<0.001)$, as illustrated in Fig. 4

Table 2 shows the final outcome at the end of the study with a mean duration of follow-up $22.7 \pm 9.9$ months. The success rate was $80.4 \%$,

Table 1: Basic clinical characteristics

\begin{tabular}{ll}
\hline Variables & Value \\
\hline Number & 46 \\
Age (years), mean \pm SD (range) & $44.5 \pm 2.5(39-49)$ \\
Parity, mean \pm SD (range) & $3.6 \pm 0.9(2-6)$ \\
BMI, mean \pm SD (range) & $26.1 \pm 1.8(22-29)$ \\
Bleeding volume, mean \pm SD (range) & $144.1 \pm 25.9(100-200)$ \\
Dysmenorrhea, mean \pm SD (range) & $3.65 \pm 1.04(2-6)$ \\
Mild dysmenorrhea, $\mathrm{n}(\%)$ & $19(41.3)$ \\
Moderate dysmenorrhea, $\mathrm{n}(\%)$ & $27(58.7 \%)$ \\
Uterine volume, mean $\pm S D($ range) & $139.8 \pm 33.2(90-240)$ \\
Past surgical history, $\mathrm{n}(\%)$ & \\
Curettage, $\mathrm{n}(\%)$ & $8(17.4)$ \\
CS, $\mathrm{n}(\%)$ & $9(19.6)$ \\
Others, $\mathrm{n}(\%)$ & $1(2.2)$ \\
\hline
\end{tabular}

SD: Standard deviation, range (minimum - maximum)

Table 2: Final outcome at the end of the study

\begin{tabular}{ll}
\hline Variables & Value \\
\hline Final outcome & $37(80.4)$ \\
Success implantation, n (\%) & $9(19.6)$ \\
Failure, n (\%) & $22.7 \pm 9.9(3-32)$ \\
Duration of follow-up (months), mean \pm SD (range) & $4(8.7)$ \\
Hysterectomy, n (\%) &
\end{tabular}

SD: Standard deviation, range (minimum - maximum)

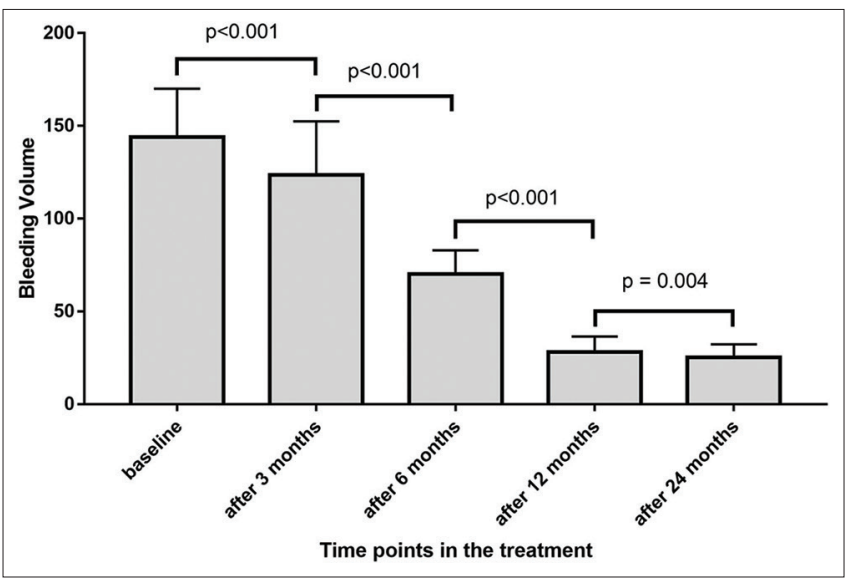

Fig. 1: Change in bleeding volume 
and the failure rate was $19.6 \%$ (expulsion+failure to show response), 4 of them end up with hysterectomy and histopathology then after confirm the diagnosis of adenomyosis.

Bleeding volume and uterine volume at baseline were significantly higher in patients with failure outcome; baseline $\mathrm{Hb}$ was significantly lower in patients with failure outcome; as illustrated in Table 3.

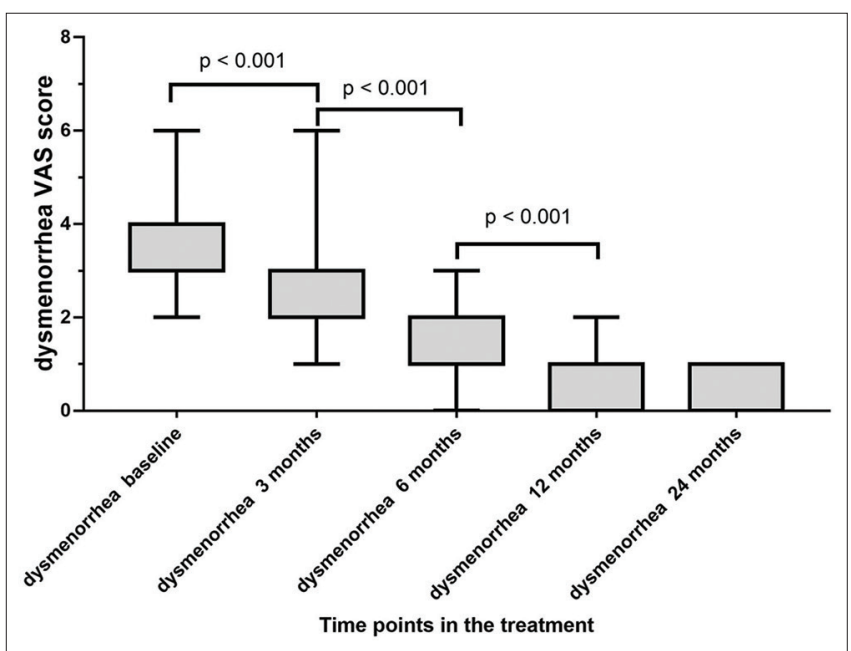

Fig. 2: Boxplot of the change in dysmenorrhea using visual analog pain scale score

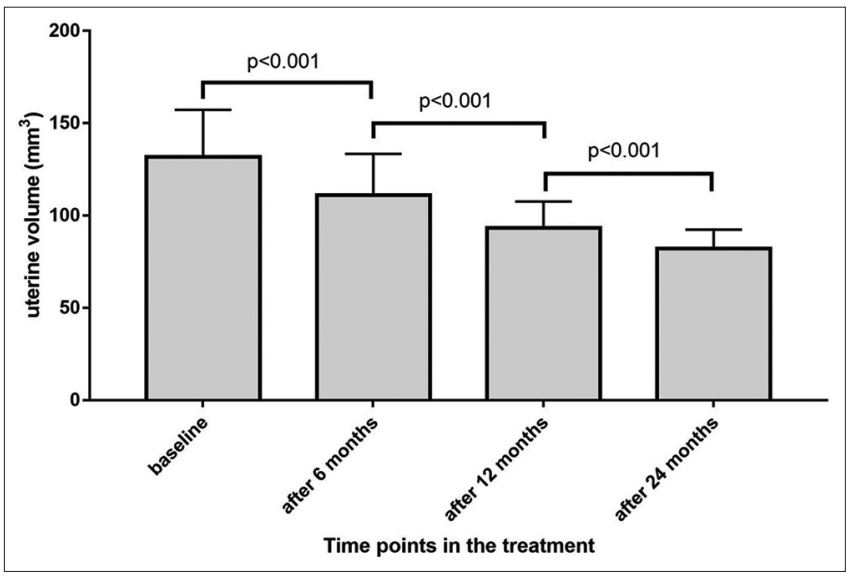

Fig. 3: Uterine volume change during the treatment periods

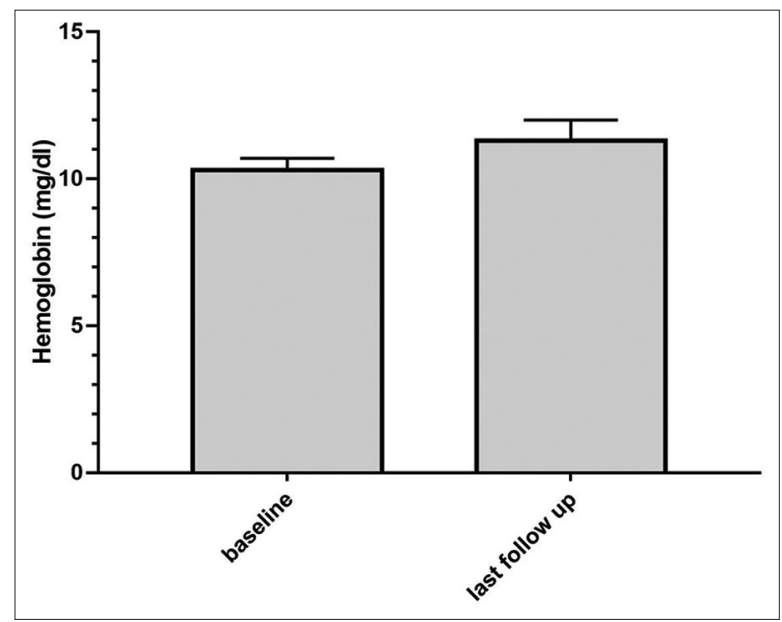

Fig. 4: Change in hemoglobin in the study
Bleeding volume and $\mathrm{Hb}$ had good ability to predict failure of implantation, while uterine volume had excellent ability to predict failure. Bleeding volume above 160 had high positive predictive value (PPV) which indicates it will more $45 \%$ increase in the post-test probability for predicting failure, uterine volume above 155 had also strong increase in predicting failure, and baseline $\mathrm{Hb}$ had slight increase in the post-test probability for predicting failure of implantation, as illustrated in Table 4 and Fig. 5. Duration of $\leq 6$ months best predict failure of treatment, as illustrated in Table 4.

\section{DISCUSSION}

LNG-IUS is used as an effective treatment reducing adenomyosisassociated menorrhagia with a significant increase in $\mathrm{Hb}$, hematocrit, and serum ferritin $[11,20,21]$

In our study, there was a significant reduction in bleeding volume/ cycle 3 months, 6 months, 1 year, and continue to decrease 2 years after insertion of Mirena. Dysmenorrhea also showed significant improvement 3, 6 months, and 1 year after Mirena insertion. Clinical response was assessed objectively by significant improvement in $\mathrm{Hb}$ level throughout the follow-up period.

On the other hand, uterine volume decreased significantly in the first 6 months of using Mirena and continues to decrease significantly over the $1^{\text {st }}$ and $2^{\text {nd }}$ year - the period of the study. This result was in agreed with Lee et al. who showed that mean uterine volume decreased in patients with adenomyosis 6 months after Mirena insertion as well as it shows significant improvement in the VAS and PABC scores [22]. However, Cho et al. study revealed that the efficacy of the LNG-IUS on uterine volume may begin to decrease in 2 years after its insertion [14].

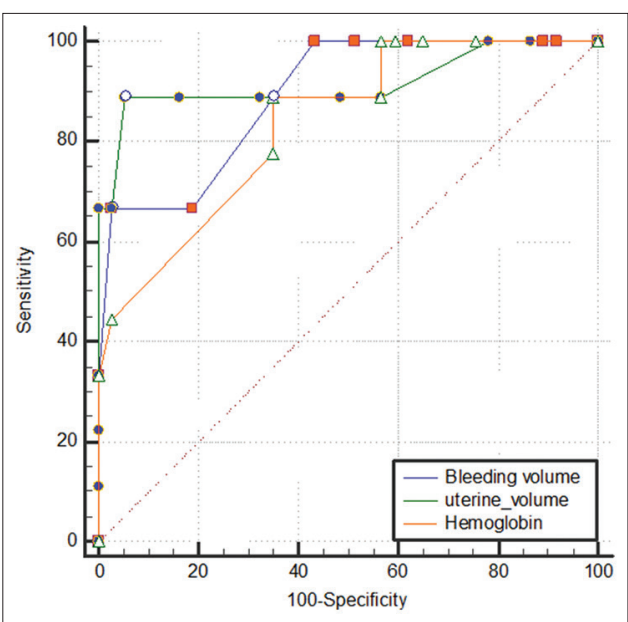

Fig. 5: ROC curve of the predictors of failure of implantation

Table 3: Comparison between different variables in relation to the outcome of implantation

\begin{tabular}{llll}
\hline Variables & \multicolumn{2}{l}{ Outcome } & p \\
\cline { 2 - 3 } & Failure & Success & \\
\hline Number & 9 & 37 & \\
Age, mean \pm SD & $44.0 \pm 2.1$ & $44.6 \pm 2.6$ & 0.546 \\
Parity, mean \pm SD & $3.4 \pm 0.9$ & $3.7 \pm 0.9$ & 0.509 \\
BMI, mean \pm SD & $26.6 \pm 1.1$ & $26.0 \pm 2.0$ & 0.399 \\
Bleeding volume, mean \pm SD & $176.7 \pm 21.8$ & $136.2 \pm 20.0$ & $<0.001$ \\
Dysmenorrhea score, & $4(3-4)$ & $4(3-4)$ & 0.839 \\
median (IQR) & & & \\
Uterine volume baseline, & $182.2 \pm 35.3$ & $129.5 \pm 23.3$ & $<0.001$ \\
mean \pm SD & & & \\
Baseline Hb, mean \pm SD & $10.0 \pm 0.2$ & $10.3 \pm 0.3$ & $<0.001$ \\
\hline SD: Standard deviation & & &
\end{tabular}


Table 4: Utility of various predictors for failure in implantation of Marina at baseline

\begin{tabular}{lllllll}
\hline Variables & AUC & Interpretation & Cut point & PPV (\%) & NPV (\%) & +LH \\
\hline Bleeding volume & 0.892 & Good & $>160$ & 85.7 & 92.3 \\
Uterine volume & 0.916 & Excellent & $>155$ & 80 & 24.67 & 0.34 \\
Hb & 0.833 & Good & $\leq 10.1$ & 38.1 & 9.12 \\
Duration (months) & 1.0 & Excellent & $\leq 6$ & 100 & 96.0 & 100 \\
\hline
\end{tabular}

PPV: Positive predictive value, NPV: Negative predictive value, +LH: Positive likely hood ratio, -LH: Negative likely hood ratio. Hb: Hemoglobin

The current study shows a success rate of $80.4 \%$ and the failure rate of $19.6 \%$ ( 9 patients out of 46 patients - 8 of them had expulsion of the device, and one showed failure of response) and duration of $\leq 6$ months best time to predict failure after LNG-IUD insertion. Lee et al. study showed a failure rate of about $21.6 \%$ and median time to failure was 6.7 months [22]. MerkiFeld et al. [23] and Socolov et al. [24] showed 15\% and 10.7\% failure rate, respectively, and that decreased within 1 year after LNG-IUD insertion.

Factors that can predict LNG-IUD treatment response or discontinuation due to expulsion or failure to show a response in women with adenomyosis were not well assessed $[5,14]$.

In our study, we use multivariate analysis to detect possible factors that can predict response to Mirena before its use in adenomyosis.

This analysis showed that the bleeding volume and $\mathrm{Hb}$ had good ability to predict failure of implantation, while uterine volume had excellent ability to predict failure. Bleeding volume above 160 had high PPV - with more than $45 \%$ increase in the post-test probability for predicting failure.

Uterine volume above $155 \mathrm{~cm}^{3}$ had also strong increase in predicting failure. The cutoff value of more than $155 \mathrm{~cm}^{3}$ was similar to that seen by Lee et al. study which showed that the optimum cutoff value of uterine volume of $>150 \mathrm{~cm}^{3}$ was significantly associated with LNG-IUD failure [22]. Zhang et al., on the other hand, used the uterine volume of $180 \mathrm{~cm}^{3}$ as a cutoff level to predict failure [25].

\section{CONCLUSION}

LNG-IUS is an effective option in treating symptomatic adenomyosis in term of time to response and duration of response. The presenting $\mathrm{Hb}$, menstrual blood loss, and uterine volume are useful predictors of response.

\section{ACKNOWLEDGMENTS}

This study was supported by the Department of Obstetrics and Gynecology in Al-Mustansiriyah Medical College and the Infertility clinic in Al-Yarmouk Teaching Hospital/Baghdad/Iraq.

\section{AUTHOR'S CONTRIBUTIONS}

All authors certify that they have participated sufficiently in work to take public responsibility for the content, including participation in the concept, design, analysis, writing, or revision of the manuscript.

\section{CONFLICTS OF INTEREST}

None of the authors have no conflicts of interest.

\section{REFERENCES}

1. Farquhar C, Brosens I. Medical and surgical management of adenomyosis. Best Pract Res Clin Obstet Gynaecol 2006;20:603-16

2. Vercellini P, Viganò P, Somigliana E, Daguati R, Abbiati A, Fedele L, et al. Adenomyosis: Epidemiological factors. Best Pract Res Clin Obstet Gynaecol 2006;20:465-77.

3. Krentel H, Cezar C, Becker S, Di Spiezio Sardo A, Tanos V, Wallwiener M, et al. Review article from clinical symptoms to MR imaging: Diagnostic steps in adenomyosis. BioMed Res Int 2017;2017:6.

4. Brucker SY, Huebner M, Wallwiener M, Stewart EA, Ebersoll S, Schoenfisch B, et al. Clinical characteristics indicating adenomyosis coexisting with leiomyomas: A retrospective, questionnaire-based study. Fertil Steril 2014;101:237-410.
5. Yoo HJ, Lee MA, Ko YB, Yang JB, Kang BH, Lee KH, et al. The efficacy of the levonorgestrel-releasing intrauterine system in perimenopausal women with menorrhagia or dysmenorrhea. Arch Gynecol Obstet 2012;285:161-6.

6. Dash S, Mishra J, Behera SS, Rout S. Therapeutic efficacy of levonorgestrel intrauterine system as an alternative to hysterectomy for management of heavy menstrual bleeding in perimenopausal women. Asian J Pharm Clin Res 2018;11:289-92.

7. Fedele L, Bianchi S, Frontino G. Hormonal treatments for adenomyosis. Best Pract Res Clin Obstetr Gynaecol 2008;22:333-9.

8. Ozdegirmenci O, Kayikcioglu F, Akgul MA, Kaplan M, Karcaaltincaba M, Haberal A, et al. Comparison of levonorgestrel intrauterine system versus hysterectomy on efficacy and quality of life in patients with adenomyosis. Fertil Steril 2011;95:497-502.

9. Fraser IS. Non-contraceptive health benefits of intrauterine hormonal systems. Contraception 2010;82:396-403

10. Sabbioni L, Petraglia F, Luisi S. Non-contraceptive benefits of intrauterine levonorgestrel administration: Why not? Gynecol Endocrinol 2017;33:822-9.

11. Fedele L, Bianchi S, Raffaelli R, Portuese A, Dorta M. Treatment of adenomyosis-associated menorrhagia with a levonorgestrel-releasing intrauterine device. Fertil Steril 1997;68:426-9.

12. Maruo T, Laoag-Fernandez JB, Pakarinen P, Murakoshi H, Spitz IM, Johansson E, et al. Effects of the levonorgestrel-releasing intrauterine system on proliferation and apoptosis in the endometrium. Hum Reprod 2001;16:2103-8

13. Critchley HO, Wang H, Kelly RW, Gebbie AE, Glasier AF. Progestin receptor isoforms and prostaglandin dehydrogenase in the endometrium of women using a levonorgestrel-releasing intrauterine system. Hum Reprod 1998;13:1210-7.

14. Cho S, Nam A, Kim H, Chay D, Park K, Cho DJ, et al. Clinical effects of the levonorgestrel-releasing intrauterine device in patients with adenomyosis. Am J Obstet Gynecol 2008;198:373, e1-7.

15. Higham JM, O'Brien PM, Shaw RW. Assessment of menstrual blood loss using a pictorial chart. Br J Obstet Gynaecol 1990;97:734-9.

16. Dixon JS, Bird HA. Reproducibility along a $10 \mathrm{~cm}$ vertical visual analogue scale. Ann Rheum Dis 1981;40:87-9.

17. Dartmouth K. A systematic review with meta-analysis: The common sonographic characteristics of adenomyosis. Ultrasound 2014;22:148-57.

18. Verit FF, Yucel O. Endometriosis, leiomyoma and adenomyosis: The risk of gynecologic malignancy. Asian Pac J Cancer Prev 2013;14:5589-97.

19. Venugopalan SK, Pandian NS, Pavani M, Rao TS, Rajini Y, Khadeer SK, et al. abnormal uterine bleeding in reproductive women: Diagnosis, management and treatment. Asian J Pharm Clin Res 2015;8:42-5.

20. Bahamondes L, Valeria Bahamondes M, Shulman LP. Non-contraceptive benefits of hormonal and intrauterine reversible contraceptive methods. Hum Reprod Update 2015;21:640-51.

21. Kelekci S, Kelekci KH, Yilmaz B. Effects of levonorgestrelreleasing intrauterine system and T380A intrauterine copper device on dysmenorrhea and days of bleeding in women with and without adenomyosis. Contraception 2012;86:458-63.

22. Lee $\mathrm{KH}$, Kim JK, Lee MA, Ko YB, Yang JB, Kang BH, et al. Relationship between uterine volume and discontinuation of treatment with levonorgestrel-releasing intrauterine devices in patients with adenomyosis. Arch Gynecol Obstet 2016;294:561-6.

23. Merki-Feld GS, Schwarz D, Imthurn B, Keller PJ. Partial and complete expulsion of the multiload 375 IUD and the levonorgestrel-releasing IUD after correct insertion. Eur J Obstet Gynecol Reprod Biol 2008;137:92-6.

24. Socolov D, Blidaru I, Tamba B, Miron N, Boiculese L, Socolov R, et al. Levonorgestrel releasing-intrauterine system for the treatment of menorrhagia and/or frequent irregular uterine bleeding associated with uterine leiomyoma. Eur J Contracept Reprod Health Care 2011;16:480-7.

25. Zhang P, Song K, Li L, Yukuwa K, Kong B. Efficacy of combined levonorgestrel-releasing intrauterine system with gonadotropinreleasing hormone analog for the treatment of adenomyosis. Med Princ Pract 2013;22:480-3. 